\title{
Percepção Ambiental dos Moradores Ribeirinhos do Médio Itapecuru em Rosário-MA como subsídio a uma Proposta de Educação Ambiental
}

Adriana Araújo Coelho ${ }^{1}$

\begin{abstract}
RESUMO: Estudo da percepção ambiental da população ribeirinha ${ }^{3}$ da cidade de Rosário MA, situada no médio Itapecuru. Inicialmente fez-se o reconhecimento da área em estudo, através de observação e conversa informal com moradores. Aplicou-se questionários aos moradores da área, visando analisar o atual quadro ambiental. Os resultados mostram que o Rio Itapecuru está sofrendo intensa agressão ambiental pela ocupação irregular, desmatamento, agricultura desenvolvida nas margens do rio e poluição por resíduos sólidos. Os dados indicam a necessidade de trabalho de educação ambiental na região envolvendo diálogo com abertura entre comunidade e pesquisadores, a fim de promover mudanças ambientais positivas no médio Itapecuru.
\end{abstract}

Palavras-chave: percepção ambienta; população; educação ambiental.

\section{INTRODUÇÃO}

Manter o equilíbrio ambiental tem sido um desafio para a humanidade, levando-se em consideração que os recursos naturais disponibilizados para suprir as necessidades do homem começam a apresentar sinais de escassez. Esse fato pode ser percebido pela exploração irracional desses recursos, o avanço populacional, bem como o estabelecimento de atividades interventoras e transformadoras do ambiente natural.

De fato, a relação homem-natureza, não tem se dado de forma adequada. Tal comportamento pode ser explicado pelo "descompromisso dos indivíduos para com a participação na resolução dos problemas ambientais; esse descompromisso é, ao mesmo tempo, resultado de suas relações sociais historicamente estabelecidas" Tozoni-Reis (2004, p. 2).

Neste quadro, as preocupações com o ambiente, em geral, e com a água apropriada para o consumo, em particular, adquirem especial importância, pois as demandas estão se tornando cada vez maiores, sob o impacto do crescimento acelerado da população e do maior uso da água. Entretanto, a qualidade das águas da terra, vem sendo degradada intensamente, e esse processo pode logo ser irreversível, principalmente, nas áreas mais densamente povoadas dos países emergentes, como o Brasil (REBOUÇAS; BRAGA; TUNDISI, 2002).

O Brasil possui a maior disponibilidade de água doce do globo, concentrando-se em suas terras, cerca de $12 \%$ do total mundial. Assim o problema brasileiro com a água está relacionado à má distribuição, que é extremamente irregular e ao uso inadequado.

A suposta fartura hídrica do Brasil é ilusória;

\footnotetext{
1 Especialista em educação ambiental e em ciências com habilitação em biologia, coordenadora de tutores do curso de especialização em educação do campo na modalidade a distância - UEMA
} 
O descompasso está no fato de, apesar de a região Norte possuir $68,5 \%$ da nossa água doce, ela abriga apenas $6,83 \%$ da população; o Nordeste, com $3,3 \%$ de água, a população é de $28,94 \%$ do total do país. A região Sudeste tem $6 \%$ de água e $42,73 \%$ da população (FILHO, 2010, p. 127).

O Maranhão apesar de ser um estado que pertence a uma das regiões menos favorecidas no que se refere à demanda hídrica, apresenta um quadro bastante significativo desse recurso, visto que dispõe de 12 bacias hidrográficas, distribuídas por todo o estado. Entre estas, merece destaque a do Itapecuru que se constitui em uma das mais importantes do Maranhão, visto que abrange "uma área de $52.972 \mathrm{Km}^{2}$ (mais de $15 \%$ do território do estado). O rio Itapecuru tem um curso de $1.048,66 \mathrm{Km}^{2}$, irriga mais de 50 municípios, dessedentando 2,5 milhões de habitantes" UEMA (2005, p. 12).

O rio Itapecuru está passando por intenso processo de degradação, pois "além do desmatamento da mata ciliar, que favorece o assoreamento, existe o lançamento dos resíduos, que são oriundos das cidades localizadas à sua margem" UEMA (2005 p. 12). Entre elas destaca-se o município de Rosário, onde a população que reside às margens do rio contribui intensamente para o processo de poluição desse manancial.

Tozoni-Reis (2004, p. 23) ressalta que "a Educação Ambiental como mediadora dessa relação (homem-natureza) se estabelece sobre a idéia de conscientização, na articulação entre conhecimentos, valores, atitudes e comportamentos, podendo promover a transformação radical da sociedade atual". Dessa forma, a Educação Ambiental é, sem sombra de dúvidas, a ferramenta transformadora das relações do ser humano com o seu meio ambiente, "alicerçada num constante processo de ação-reflexão-ação, amplamente difundido por Paulo Freire” (LENCIONE et al., 2005, p. 224). (grifo do autor).

Esse percurso de aprendizagem ambiental exige a junção do saber científico e do saber das comunidades tradicionais. No contexto do presente trabalho, atividades de educação ambiental só serão significativas, caso sejam considerados os saberes dos ribeirinhos e demais usuários dos recursos do médio Itapecurú. Para isso, será necessário conhecer qual é a leitura da paisagem que a comunidade faz atualmente da região a ser estudada.

"Ler" o meio ambiente é apreender um conjunto de relações sociais e processos naturais, captando as dinâmicas de interação entre as dimensões culturais, sociais e naturais na configuração de dada realidade socioambiental. Para chegar a isso, não basta observar passivamente o entorno, mas é importante certa educação do olhar, aprender a "ler" e compreender o que se passa à volta da comunidade. Uma "leitura da paisagem", é, portanto, um roteiro de ação participativa para levantamento das características de dada região em estudo (CARVALHO; GRUN, 2005).

Assim, o objetivo do presente trabalho foi analisar as condições ambientais do médio Itapecuru no município de Rosário - MA, a partir da percepção ambiental da comunidade, apontando sugestões para atividades de Educação Ambiental que visem a melhoria da qualidade de vida das pessoas que usam direta ou indiretamente os recursos naturais na região.

\section{METODOLOGIA}

Trata-se de um estudo de percepção ambiental dos ribeirinhos, residente no município de Rosário - MA, com abordagens quantitativas e qualitativas, levantadas junto à comunidade, através de observação da área, seguida de aplicação de questionário contendo questões fechadas e abertas.

Inicialmente fez-se o levantamento bibliográfico da literatura existente sobre o tema trabalhado, seguido de visita "in loco" para reconhecimento da área de estudo, foram observados e identificados os problemas socioambientais, através de contato direto com moradores da área. 
Para sistematização da pesquisa e após a investigação informal elaborou-se um instrumento de coletas de dados - questionário - composto por questões fechadas e abertas a ser aplicado aos moradores, cujas atitudes e opiniões pretendiam-se conhecer.

O questionário foi aplicado a 30 moradores ribeirinhos da cidade de Rosário -MA. Entre as questões abordadas, destacaram-se os seguintes aspectos: condições de moradia, distribuição dos serviços de saneamento básico (esgotamento sanitário, abastecimento de água tratada, coleta e destino do lixo, etc.), tipos de lixo encontrado com mais frequência no rio, importância na preservação das matas ciliares, assoreamento do rio e outros problemas ambientais que interfere na qualidade de vida dos moradores.

\section{PERCEPÇÃO AMBIENTAL DA COMUNIDADE}

Foram aplicados 30 questionários em residências e áreas de lazer situadas nas proximidades da porção, curso médio do rio Itapecuru que atravessa a cidade de Rosário - MA.

Os resultados apontaram que $77 \%$ dos entrevistados reside nas proximidades do rio há mais de 10 anos. Esse resultado pode estar relacionado a fatores culturais, considerando que a população brasileira sempre procurou instalar-se em áreas próximas a mananciais, por considerar a facilidade no cultivo dos alimentos e assim garantir o suprimento das necessidades básicas (MUCCl, 2005).

Todos os moradores envolvidos na pesquisa afirmaram que possuem abastecimento de água de tratada e ressaltam que consumir água que passa por um processo de tratamento é fundamental à manutenção de um bom estado de saúde. Existem estimativas da Organização Mundial de Saúde (OMS) em 2004 de que cerca de 5 milhões de mortes anuais são ocasionadas por doenças de veiculação hídrica e pelo menos um quarto da humanidade permanece sem acesso à água segura e saneamento.

Ao serem questionados sobre o destino do lixo que é por eles produzidos (gráfico 1), $83 \%$ responderam que colocam o lixo na lixeira e $7 \%$ afirmaram jogar em qualquer lugar. Ao comparar os resultados dos questionários e observando a área de estudo, foi possível identificar que os resíduos gerados pelos moradores são na sua maioria lançados diretamente nas margens do rio. Assim resíduos sólidos orgânico-inorgânicos são continuamente jogados ao meio ambiente. Estes incontestavelmente terminam nos ecossistemas aquáticos e os efeitos negativos provocados nesses ambientes são diversos.

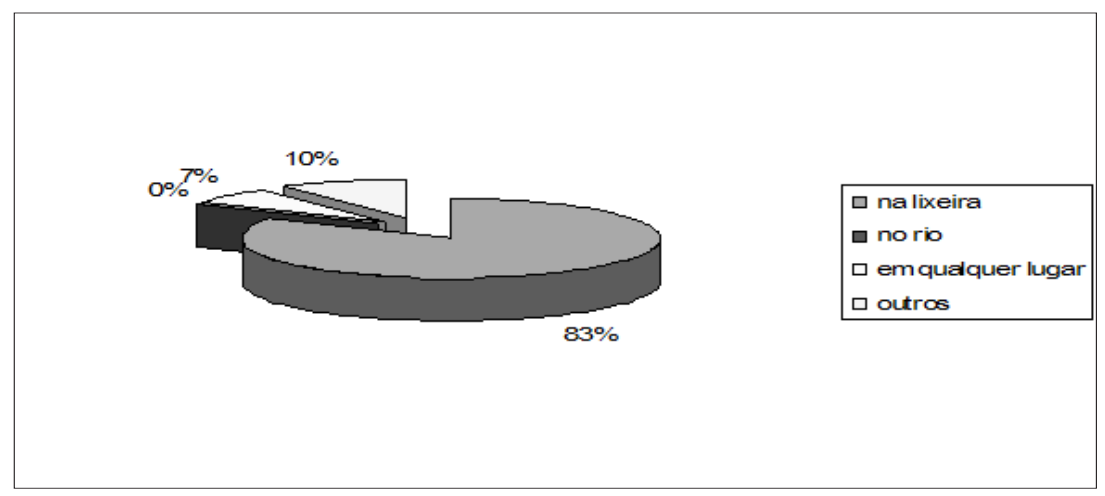

Figura 1: Destino do lixo gerado pelos ribeirinhos do município de Rosário - MA. 
Andrade (1994) ressalta que o lixo é um dos problemas ambientais mundiais mais preocupantes, pois diz respeito a cada um de nós. Dessa forma, abordar a problemática da produção e destino do lixo é um desafio, cuja solução passa pela compreensão do individuo como parte atuante no meio em que vive.

Conforme respostas obtidas através da aplicação dos questionários sobre os fatores que mais contribuem para o assoreamento do rio (figura 2), $57 \%$ responderam que é o desmatamento e $23 \%$ afirmaram ser o lançamento de lixo. Um dos entrevistados enfatizou que: "nós precisamos desmatar essas áreas para plantar os alimentos pois não temos outro terreno, mesmo sabendo que isso está matando o rio, pois antes ele era cheio e tinha muitos peixes e agora o rio está secando muito rápido".

Dessa forma, "problemas com desmatamento e poluição já são reconhecidos pela população leiga como os principais responsáveis pela morte dos rios e consequentemente pela escassez de água" Diniz e Matheus (2005, p.255) No entanto, grande parte da área desmatada é conseqüência da ausência de área apropriada para realizar suas plantações, visto que, os moradores necessitam cultivar esses solos para garantir seu sustento. Assim, a prática de cultura, cultivo de vazante é muito freqüente em toda a extensão do rio, inclusive na porção que atravessa a cidade de Rosário - MA.

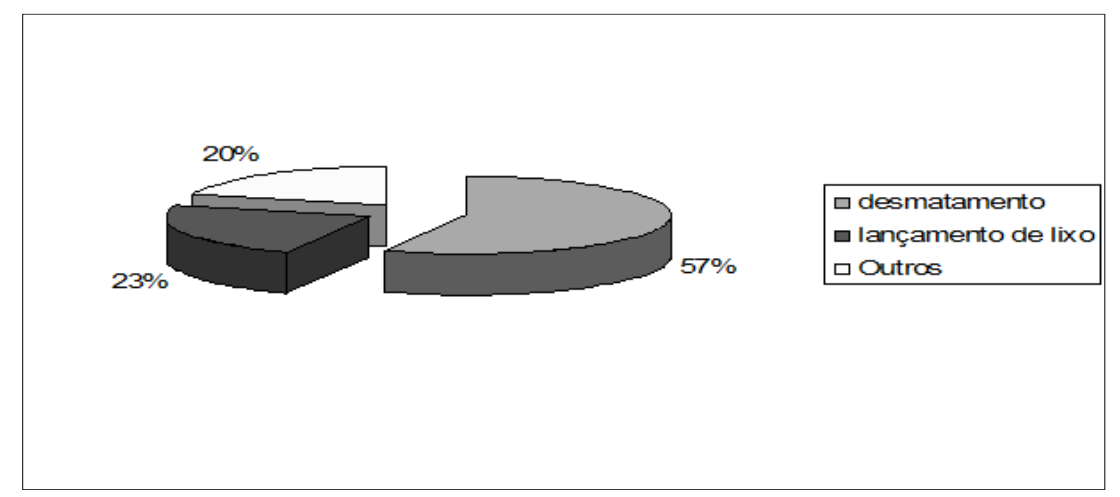

Figura 2: Fatores que mais contribuem para o assoreamento do rio Itapecuru na cidade de Rosário - MA.

O gráfico 4 apresenta o percentual das respostas quanto ao tipo de lixo encontrado com mais frequência no rio, onde $73 \%$ dos entrevistados responderam que é o plástico e $10 \%$ afirmaram tratar-se de resíduos oriundos das construções. Além dos resíduos sólidos encontrados às margens do rio, percebeu-se durante a observação da área que existe outro agravante desta problemática, trata-se do esgoto doméstico que continua sendo o principal responsável pela poluição hídrica em nosso país, uma vez que, em muitas regiões, não passa nenhum tipo de tratamento sendo lançado in natura nos corpos receptores (MUCCl, 2005). Despejar resíduos as margens dos rios tem sido infelizmente, a prática mais usual dos moradores ribeirinhos e isso reflete intensamente na qualidade de vida.

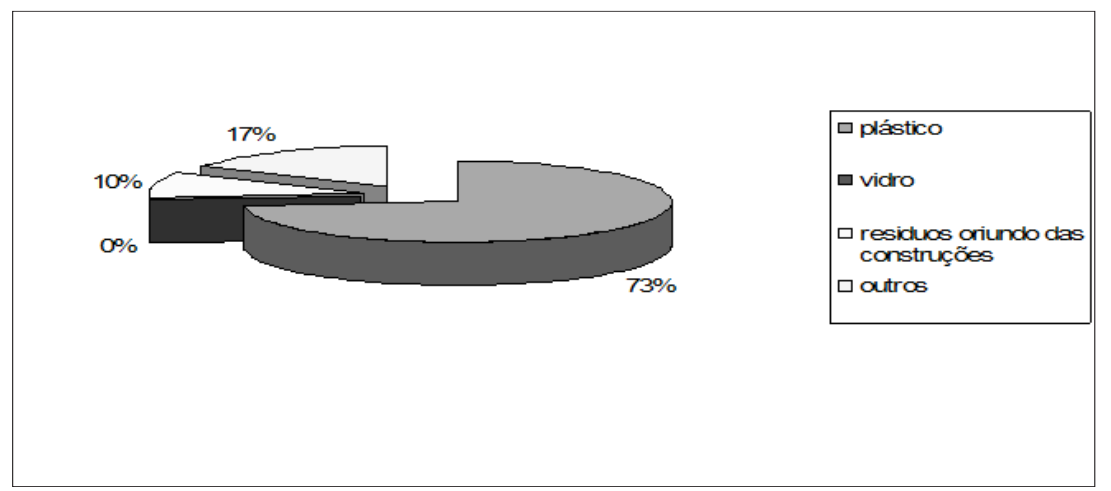

Figura 3: Tipo de lixo encontrado com mais frequência na porção do rio Itapecuru que atravessa o município de Rosário - MA. 
Os resultados apresentados na figura 4, mostram os percentuais de respostas referentes aos problemas existentes com relação ao lixo acumulado nas margens do rio e $63 \%$ dos entrevistados responderam tratar-se dos mais diversos problemas (doenças, mal cheiro, entre outros). Uma das entrevistadas acrescentou que: "já olhei muitas pessoas jogarem animal morto no rio, e depois vejo as crianças tomando banho". O quadro exige mudança de postura em relação aos cuidados que se deve ter para com os mananciais locais.

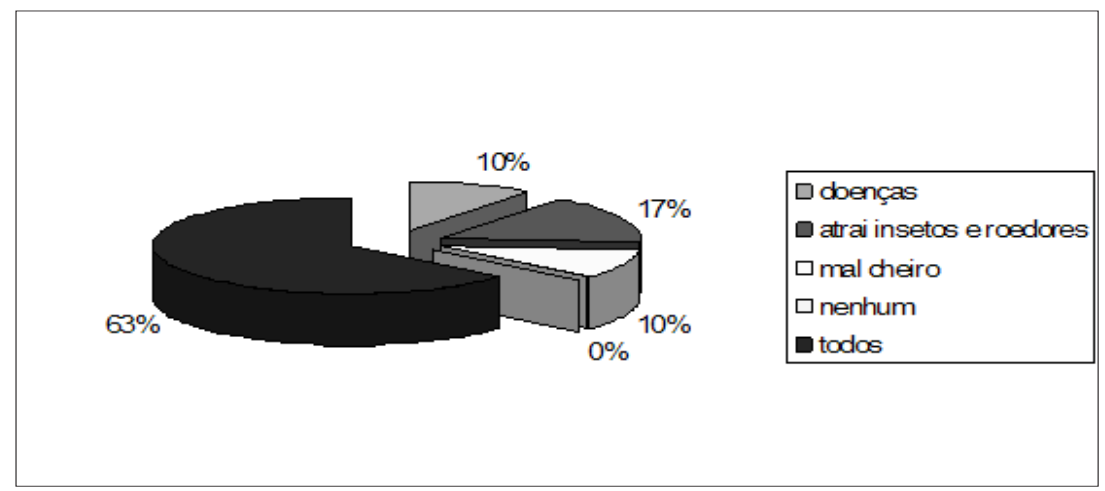

Figura 4: Problemas existentes com relação ao lixo acumulado nas margens do rio Itapecuru no município de Rosário -MA.

Ao serem questionados sobre a importância em preservar as matas ciliares (figura 5), $53 \%$ responderam que serve para evitar o assoreamento do rio e $7 \%$ disseram que a vegetação mantém o rio limpo. É importante destacar que o Rio Itapecuru foi durante muitos anos o elo entre as regiões maranhenses, transportando produções agrícolas e comerciais. Em suas margens funcionaram os primeiros engenhos de açúcar e se cultivou com êxito algodão da melhor qualidade (MEDEIROS, 2001).

Dessa forma, essas atividades propiciaram o desenfreado desmatamento, que se constitui em um dos principais responsáveis pela degradação da bacia do Itapecuru, pois a remoção da mata ciliar contribui para a intensificação do processo de assoreamento, que é bastante comum em cidades ribeirinhas. Com isso a navegabilidade em alguns pontos e a ligação entre a maioria dos seus afluentes foram extremamente afetadas.

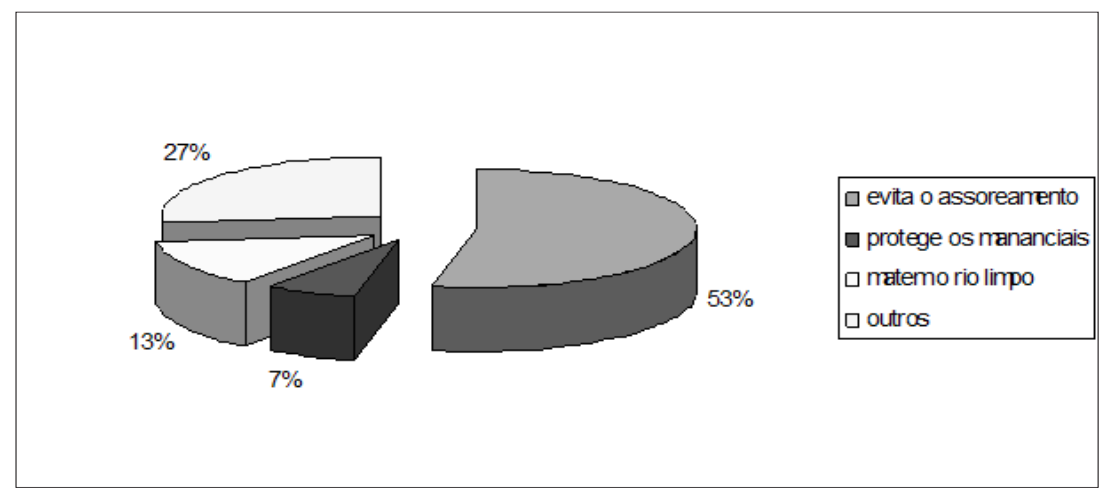

Figura 5: Importância de se preservar as matas ciliares do rio Itapecuru no município de Rosário - MA.

Quando questionados sobre o interesse em participar de projetos voltados para questão ambiental, todos responderam que tem interesse (figura 6). Um dos moradores destacou a necessidade de eventos voltados para a amenização da problemática ambiental, especificamente envolvendo os ribeirinhos, em sua fala chamou atenção para a ineficácia das políticas públicas e relatou que: "os moradores dessa área não se preocupam com o desmatamento das margens do rio e vivem lançando sujeira no rio". Dessa forma, a Educação Ambiental se apresenta como uma importante ferramenta no contexto social. 


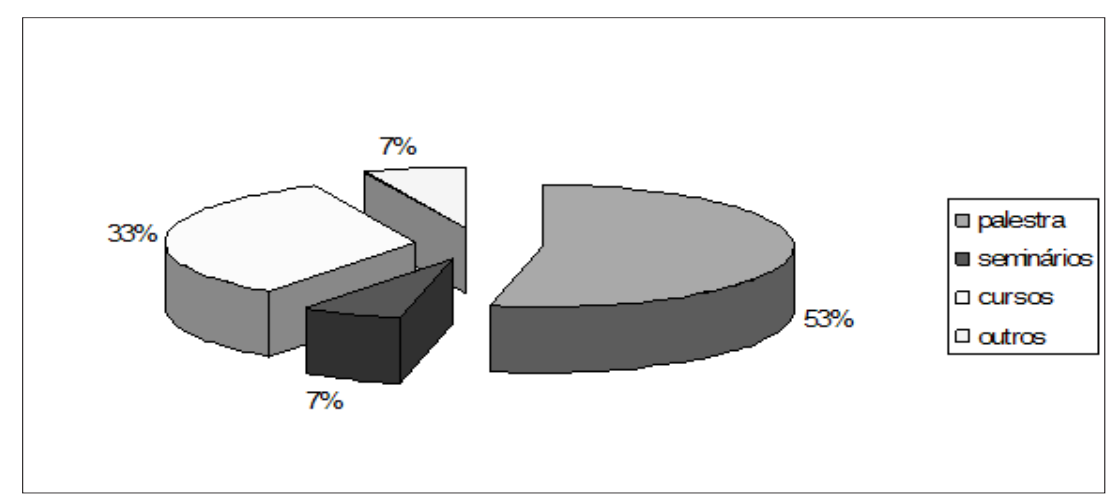

Figura 6: Interesse em participar de atividades voltadas para questão ambiental

De fato, não se pode negar o significativo papel que a EA representa no atual contexto ambiental. Trata-se de uma ferramenta destinada a reformular comportamentos humanos, na medida em que, possibilita-os repensar suas ações sobre o ambiente. Assim, a partir do momento em que cada um internalizar a necessidade dessa mudança e fazer a sua parte, será possível promover o equilíbrio ambiental.

\section{UMA PROPOSTA DE EDUCAÇÃO AMBIENTAL PARA A COMUNIDADE}

Como instrumento de sensibilização para os problemas ambientais do Médio Itapecuru, faz-se necessário o retorno do conhecimento construído para a comunidade analisada, visando à realização de palestras informativas e outras atividades educativas capazes de socializar os resultados obtidos nesta pesquisa. Tais atividades educativas terão o papel de contribuir com a mudança de atitude da população, considerando que "o processo de Educação ambiental embora seja lento e sem resultados imediatos, é essencial para que os indivíduos envolvidos se percebam sujeitos sociais" Lencione et al., (2005, p. 223).

Dessa forma, a participação do cidadão em eventos que envolvem a problemática ambiental estimula a mudança de comportamento e propicia a construção de novos valores éticos, na medida em que, desperta no individuo a criticidade, sobre suas atitudes, tornando-os conscientes dos problemas ambientais.

Com essa maneira de pensar, é que os movimentos em defesa do ambiente natural veem na educação ambiental seja ela formal e informal, uma ferramenta indispensável na forma de capacitação dos cidadãos, visto que propicia aos diversos atores sociais condições para que participem dos mais variados processos decisórios. Pois os problemas que nos cercam são graves e exigem respostas imediatas, ainda que parciais preliminares e incertas (GRUN, 1996). Assim, nas propostas de trabalho com educação ambiental nas comunidades do médio Itapecuru sugere-se que sejam inseridos os seguintes aspectos:

- Diálogo como abertura - trata-se de nos colocarmos enquanto pesquisadores frente ao outro numa atitude de escuta, considerando que no encontro será possível acessar um conhecimento que até então não estava disponível. Devese agir na busca de um saber que não se sabe, visando interferir positivamente no ambiente e na vida das comunidades do médio Itapecuru;

- Esclarecimento das intenções e crenças da comunidade - é necessário que cada participante assuma o desafio de ser cada vez mais honesto e transparente a respeito de suas intenções, expressões e buscas sobre os problemas e soluções para o médio Itapecuru;

- Exercício da cidadania e da política - é importante ressaltar que as discussões e ações relacionadas ao manejo do médio Itapecuru, para a sociedade de hoje e a do futuro, é tarefa a ser discutida e compartilhada democraticamente, de maneira responsável e solidária. 
- Ligação entre o local e o global - trabalhar na elaboração e na efetivação de soluções para o desenvolvimento de ações imediatas para melhoria das condições ambientais e de vida da população do médio Itapecuru, onde os participantes se confrontem com a necessidade de revervalores; de diagnosticar problemas; de discutir propostas; de debater formas para viabilizá-las, sempre de forma participativa.

Ao se colocar essas considerações, refletindo a realidade em que vivemos, fazse necessário que se realizem em curto prazo as ações que envolvem o cuidado que o homem deve ter com a área ribeirinha, de forma a assegurar as gerações futuras o abastecimento de água potável, sem a preocupação de escassez. Assim, a educação ambiental, na medida em que inserir o ambiente humano em suas práticas incorpora os processos decisórios participativos como um valor significativo a ser apreciado na proteção ambiental (LOUREIRO; LAYRARGUES ; CASTRO, 2000).

\section{CONCLUSÕES}

Os resultados obtidos neste estudo revelaram que:

- A porção do Rio Itapecuru que percorre a cidade de Rosário - MA está sofrendo intensa agressão ambiental, que são oriundas de ações antrópicas;

- Na comunidade ribeirinha do médio Itapecuru em Rosário - MA o saneamento básico é praticamente inexistente, considerando que a área é totalmente desprovida de esgotamento sanitário, o que obriga aos moradores laçarem seus resíduos sólidos e dejetos diretamente no rio, desencadeando uma série de problemas ambientais;

- Um percentual significativo dos entrevistados apontaram o desmatamento como principal responsável pelo assoreamento do rio;

- O desmatamento das margens do rio ocorre devido à necessidade dos moradores em cultivar esses solos férteis para garantir seu sustento;

- O plástico foi apontado como o tipo de lixo encontrado com mais freqüência no rio;

- Todos os entrevistados mostraram interesse em participar de projetos voltados para educação ambiental, principalmente de palestras informativas e cursos;

- Os resultados mostram a necessidade de se desenvolver um trabalho de educação ambiental na região envolvendo diálogo com abertura entre comunidade e pesquisadores, esclarecimento das intenções e crenças da comunidade, exercício da cidadania e da política, a fim de promover mudanças ambientais positivas no médio Itapecuru.

\section{REFERÊNCIAS}

ANDRADE, M. O desafio ecológico. São Paulo: Hucitec, 1994.

CARVALHO, I. C. M.; GRUN, M. Hermenêutica e educação ambiental: o educador como intérprete. In: FERRARO JÚNIOR, LUIZANTONIO(Org.). Encontros e caminhos: formação de educadoras (es) ambientais e coletivos educadores. Brasília-DF: MMA/Diretoria de Educação Ambiental, 2005.

CAVALCATE FILHO, J. R. A água como elo de identidades sociais no semiárido paraibano: estudo de caso, Cabaceiras. 2010. 196 f. Dissertação (Mestrado em 
Desenvolvimento Regional e Meio Ambiente) - Programa de Mestrado em Desenvolvimento Regional e Meio Ambiente, Centro Universitário de Araraquara, São Paulo, 2010.

GRUN, M. Ética e educação ambiental no Brasil. Campinas: Papirus, 1996.

GUARIM, V. Sustentabilidade ambiental em comunidades ribeirinhas tradicionais. In: SIMPÓSIO SOBRE RECURSOS NATURAIS E SOCIOECONÔMICO DO PANTANAL, 3., 2008. Os desafios do novo milênio. Corumbá, Mato Grosso do Sul, 2000.

LENCIONE, S.; SANTORO, M. R. R.; SEGURA, M. O.; MATHEUS, C. E. As águas que abastecem Santa Rita do Passa quatro/SP. In: Simpósio comemorativo aos 10 anos do curso de especialização em educação ambiental e recursos hídricos, 2005, São Carlos, São Paulo. Anais... São Carlos, São Paulo: USP, 2005, p. 224.

LOUREIRO, C. F. B; LAYRARGUES, P. P; CASTRO, R. S. de (Orgs.). Sociedade e meio ambiente: a educação ambiental em debate. São Paulo: Cortez, 2000.

MEDEIROS, R. Rio Itapecuru águas que correm entre pedras. São Luis: ABES, 2001.

MUCCI, J. L. N. Introdução as Ciências Ambientais. In: PHILIPPI JR., A; PELICIONI, M. C. F. (Eds.). Educação ambiental e sustentabilidade. São Paulo: Manole, 2005.

ORGANIZAÇÃO MUNDIAL DA SAÚDE. Água no mundo. 2004. Disponível em: <http:// www.estadão.com.br/ext/ciencia/agua/aguanomundo3.htm>. Acesso em: 8 jun. 2010

REIGOTA, M. O que é educação ambiental. São Paulo: Brasiliense, 2001, p. 12.

REBOUÇAS, A. da C; BRAGA, B.; TUNDISI, J. G. Capital ecológico, uso e conservação. 2 ed. São Paulo: Escrituras Editora, 2002.

TOZONI-REIS, M. F. de Campos. Educação ambiental: natureza, razão e história. Campinas, SP: Autores associados, 2004.

UNIVERSIDADE FEDERAL DO MARANHÃO. Laboratório de recursos hídricos: bacias hidrográficas. São Luis: EDUEMA, 2005. 